\title{
Advancing Virtual Patient Simulations and Experiential Learning with InterPLAY: Examining How Theory Informs Design and Design Informs Theory
}

\author{
Atsusi Hirumi, University of Central Florida \\ Kyle Johnsen, University of Georgia \\ Andrea Kleinsmith, University of Maryland, Baltimore County \\ Ramsamooj Javier Reyes, University of Central Florida \\ Diego J. Rivera-Gutierrez, Uinversity of Florida \\ Stacey Kubovec, University of Central Florida \\ Kenneth Bogert, University of Georgia \\ Benjamin Lok, University of Florida \\ Juan Cendan, University of Central Florida
}

\begin{abstract}
Design-based research examines the role of theory in informing design, and the role of design in advancing theory. During the last year of a five-year NIH grant, a team of physicians, software engineers, and instructional designers at three public universities completed a series of iterative design studies to produce the first public release of NERVE-A virtual patient (VP) simulation created to give medical students standardized experiences in interviewing, examining, and diagnosing patients with cranial nerve disorders. The last year of the project, including the results of two cycles of expert reviews, one-to-one and small group evaluations, and a field test with 119 second-year medical students are reported by Hirumi et al. (2016a, 2016b). This article augments the previous papers by examining the pedagogical foundations of NERVE in greater depth. Specifically, we detail how the InterPLAY instructional theory was applied to design NERVE, and how the development and testing of NERVE lead to advancements in InterPLAY during the last year of research and development.
\end{abstract}

Keywords: virtual patient simulations, medical simulations, design research, instructional theory, experiential learning, instructional design.

Inadequate practice and evaluation are two of the primary reasons reported by medical students for limited knowledge and confidence in conducting neurological exams (Moore \& Chalk 2009; Schon, Hart, \& Fernandez, 2002). Learning how to diagnose patients with Cranial Nerve $(\mathrm{CN})$ disorders is particularly challenging because they are rarely seen and difficult to imitate. Supervised encounters with real patients are hard to schedule because $\mathrm{CN}$ disorders are uncommon and standardized patients cannot readily reproduce disorders that affect motor nerves. Virtual patient (VP) simulations, one of five types of simulations used to facilitate medical education (Eder-Van Hook, 2004), give students substantive opportunities to gain knowledge and confidence in interviewing, examining, and diagnosing patients with $\mathrm{CN}$ palsies. VP simulations also give med- ical educators a tool for presenting clinical variations and providing standardized experiences with $\mathrm{CNs}$ and $\mathrm{CN}$ palsies.

Fueled by its potential and a five-year, $\$ 1.8$ million grant from National Institute of Health (NIH), an interdisciplinary team of faculty, staff, and students specializing in medicine, software engineering, and instructional design from three universities in the southeastern United States set out to achieve two goals: (a) to develop a virtual environment that enables medical students to rehearse their interviewing, examination, and diagnostic skills with patients presenting with cranial nerve (CN) disorders, and (b) create a tool that would enable researchers to study different aspects of VP simulations research and development (R\&D). 
To discuss the range of studies completed by the team during the five-year initiative is beyond the scope of this paper. Kleinsmith et al. (2015), Rivera-Gutierrez et al. (2014), Lyons, Johnson, Khalil, and Cendan (2014), and Johnson et al. (2014, 2013) report findings from controlled experiments completed during the first four years of $R \& D$ that compared various aspects of VP simulations to inform the design of the system and advanced VP simulation research, such as individual versus small group use of the system, use of the system under competitive versus non-competitive conditions, the use of reflective questions embedded during versus after the simulation, instructor-led content delivery versus independent self-study of the content prior to use, and the use of an open-chat versus closed menu user interface.

In addition, in Parts I and II of a two-part series published in Educational Technology Research and Development, we detailed the design and development, and the testing and integration of the Neurological Exam Rehearsal Virtual Environment (NERVE) - the first public release of the VP simulation that resulted from the final year of R\&D now available at http:// nervesim.com (Hirumi et al., 2016a, 2016b).

In this article we examine the pedagogical foundations of NERVE in greater depth by discussing how the InterPLAY instructional theory was applied to design NERVE, and how the development and testing of NERVE led to advancements in InterPLAY during the last year. This article augments Parts I and II by allowing us to further demonstrate the interactive nature of applied and basic research by highlighting the role of theory in informing design, and the role of testing in refining theory (Collins, 1992). Specifically, we review literature and the method used to generate NERVE, and examine how the last year of $R \& D$ helped answer two basic design research questions:

1. How were the principles of experiential learning and the InterPLAY instructional theory used to design NERVE?

2. How did the design and testing of NERVE advance the experiential learning principles and InterPLA $Y$ theory?

\section{Review of Literature}

Eder-Van Hook (2004) distinguishes five types of simulations used to facilitate medical education: (a) low -tech simulators (e.g., models or mannequins used to practice simple physical procedures); (b) simulated standardized patients (i.e., actors trained to role-play as patients); (c) screen-based computer simulators (e.g., programs used to train and assess clinical knowledge and decision making); (d) complex-task trainers (e.g., computer-driven physical models of body parts and environment); and (e) realistic patient simulators (e.g., computer-driven, full-length mannequins that simulate anatomy and physiology, clinical reasoning and decision making). Virtual patient (VP) simulations use interactive computer technology to integrate instructional features before, during and after key interactions with screen-based computer simulators to foster clinical reasoning and enhance learners' diagnostic capabilities.
Synthesis research comparing the effectiveness of VP simulations with alternative instructional methods supports the efficacy of VP simulations. Based on a meta-analysis of 48 studies, Cook, Erwin, and Triola (2010) conclude that VP simulations are associated with higher learning outcomes than are conventional educational methods used in medical schools. Similarly, in a meta-analytic review of 14 studies, McGaghie, Issenberg, Cohen, Barsuk, and Wayne (2011) found that simulation-based medical education is more effective than traditional, lecture-based methods $(\mathrm{ES}=0.71)$. More recently, a meta-analysis of randomized controlled studies also showed a clear positive pooled overall effect for VP simulations compared to other educational methods (Consorti, Mancuso, Nocioni, \& Piccolo, 2012). Yet, we cannot simply give students access to VP simulations and assume that they will learn. Studies report low acceptance, usage and satisfaction among medical students when learning resources, such as VP simulations, are poorly designed or not well integrated with other curricular components (Berman et al. 2009; Fischer et al. 2007).

A growing body of research now emphasizes the importance of design for facilitating medical education. "Apparently, learning outcomes depend on the quality of instructional design methods rather than on the medium used" (Huwendiek et al., 2009, p. 581). Based on a systematic review of literature, Issenberg et al.'s (2005) identified ten design features of high-fidelity medical simulations that lead to effective learning, including (a) providing feedback, (b) repetitive practice, (c) curriculum integration, (d) range of difficulty level, (e) multiple learning strategies, (f) capture clinical variation, (g) controlled environment, (h) individualized learning, (i) learning outcomes, and (j) simulation validity (e.g., realism, authenticity). By analyzing focus group interviews of Year 5 medical students who worked through eight VP simulations, Huwendiek et al. (2009) also found ten similar VP design features for fostering learning, including (a) relevance, (b) appropriate level of difficulty, (c) interactivity, (d) specific feedback, (e) appropriate use of media, (f) focus on relevant learning points, $(\mathrm{g})$ recapitulation of key learning points, (h) authenticity of the design of the web-based interface, (i) authenticity of the learning task, and (j) questions and explanations tailored to the clinical reasoning process. Issenberg et al.'s and Huwendiek et al.'s findings, along with 18 additional VP design studies published since 2006 provided insights into the nature and range of key features for designing VP simulations (Reyes \& Hirumi, 2016). To provide further context for this study, we also examined the pedagogical foundations (the learning and instructional theories, models and strategies) that were used to ground the design of key features included in the reported VP simulations.

In a review of VP design studies published since 2006, Reyes and Hirumi (2016) found that 10 out of 20 $(50 \%)$ of the authors cited models of how physicians critically reason through clinical cases, and 15/20 (75\%) referred to the use of instructional strategies for developing clinical reasoning skills to guide the design of VP simulations. Table 1 depicts the frequency in which the authors referred to the application of clinical reasoning 
Table 1

Frequency of learning theories and instructional strategies posited to guide the design of VP simulation

\begin{tabular}{|c|c|c|c|c|c|c|c|c|c|c|c|c|c|c|c|c|c|c|c|c|c|c|}
\hline & \multicolumn{22}{|c|}{ Publications } \\
\hline $\begin{array}{l}\text { Pedagogical } \\
\text { Foundation }\end{array}$ & 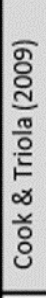 & 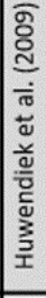 & 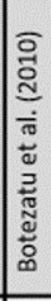 & 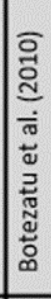 & 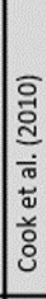 & 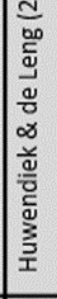 & 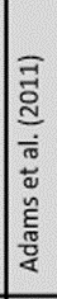 & 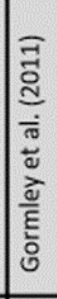 & 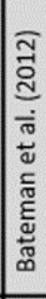 & 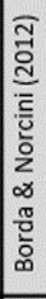 & 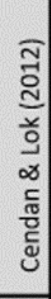 & 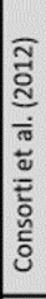 & 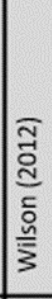 & 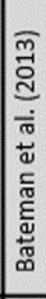 & 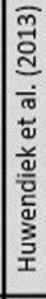 & 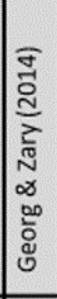 & 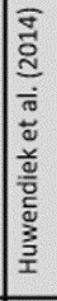 & 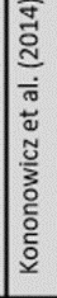 & 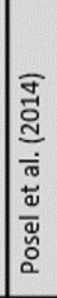 & 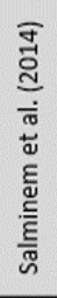 & సँّ & 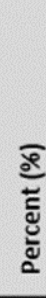 \\
\hline $\begin{array}{l}\text { Reasoning } \\
\text { Strategy }\end{array}$ & $x$ & $\mathrm{x}$ & & & $x$ & $\mathrm{x}$ & $x$ & & $x$ & & $x$ & $x$ & $x$ & & $\mathrm{x}$ & $x$ & $x$ & $x$ & $\mathrm{x}$ & $x$ & 15 & 75 \\
\hline $\begin{array}{l}\text { Reasoning } \\
\text { Model }\end{array}$ & & $\mathrm{x}$ & & & & $x$ & & & & & & $x$ & $x$ & $x$ & $\mathrm{x}$ & $x$ & $x$ & & $x$ & $x$ & 10 & 50 \\
\hline $\begin{array}{l}\text { Experiential } \\
\text { Learning }\end{array}$ & & & & & & & & & & & $\mathrm{x}$ & & & & & & & $x$ & & $x$ & 3 & 15 \\
\hline $\begin{array}{l}\text { Cognitive } \\
\text { Multimedia }\end{array}$ & & & & & $x$ & & & $x$ & & & & & & $x$ & & & & & & & 3 & 15 \\
\hline Cognitive Load & & & & & & & & & & & $x$ & & & $x$ & $x$ & & & & & & 3 & 15 \\
\hline Activity Theory & & & & & & & & & & & & $x$ & & & & & & & & & 1 & 5 \\
\hline Situated Cognition & & & & & & & & & & & & & $x$ & & & & & & & & 1 & 5 \\
\hline Blended Strategy & & & & & & & & & & & & & & & $x$ & & & & & & 1 & 5 \\
\hline
\end{tabular}

as well as other pedagogical foundations to design VP simulations, including experiential and cognitive multimedia learning theory, cognitive load and activity theory, situated cognition, and a blended instructional strategy (Reyes \& Hirumi, 2016).

Considering their primary purpose, the use of clinical reasoning models and instructional strategies as predominant frameworks for designing VP simulations is to be expected. However, we posit that in a relatively nascent field, it may be beneficial to explore alternative theories, principles, and strategies to optimize the design of VP simulations. This is not to say that VP simulations that are grounded in clinical reasoning are insufficient or inappropriate. Rather, exploring competing theories and models from other fields and disciplines, such as the psychology of learning, instructional systems design, cognitive work analysis, and adult learning, may also be useful for designing VP simulations (AHRQ, 2013).

In an early attempt to form a prescriptive theory for the design of computer-based simulations, Reige- luth \& Schwartz (1989) presented a general model and variations of the model that include recommendations for designing the instructional overlay that facilitates the introduction, acquisition, application, and assessment stages of simulations, and addresses system versus learner control issues. More recently, de Jong and van Joolingen (1998) present principles for designing simulation-based discovery learning environments based on an in-depth analysis of characteristic problems faced by students challenged with directing their own learning, and techniques for providing instructional support to facilitate and regulate key stages of the discovery learning processing, including hypothesis generation, design of experiments, and making predictions. Gredler (2004) also prescribes strategies for designing interactive, discovery learning exercises that center on modeling research skills and teaching metacognitive skills to limit extraneous cognitive load. Building on the works of Reigeluth and Schwartz, de Jong and van Jollingen, Gredler, and others, Gibbons, McConkie, Seo, and Wiley (2009) proposed theory for designing instructional simula- 
tions comprised of an array of principles for facilitating seven basic functions, including: supplying model content, implementing instructional augmentations, providing user controls, generating message units, assembling elements, executing computations, and managing data.

Organizational and educational psychologists also emphasize the importance of the instructional features embedded into training and educational simulations, and propose principles and procedures for optimizing simulation-based training (SBT). For instance, Sales and Gregory (2011) propose seven steps for maximizing the effectiveness of SBT systems based on their understanding of the science of learning, including analyzing performance history and skill inventories, deciding what tasks and competencies to address, determining the training objectives, designing scenarios with key trigger events, determining how to measure the events, observing and diagnosing performance, and giving diagnostic feedback. In contrast, Quinn (2007) distinguishes nine principles for designing engaging computer-based simulations, founded on his interpretation of learning theories and synthesis of common elements for effective entertainment and education, including: an integrated theme to contextualize learning, clear goals, appropriate challenges, evident links between learners' actions and goal achievement, learners' interest in goals and world, active choices and exploration, direction manipulation, appropriate feedback, and gaining attention.
Together, the models of clinical reasoning, the strategies for developing critical reasoning skills, and the principles for designing computer-based simulations provide alternative frameworks for grounding the design of VP simulations. In the following subsections, we illustrate the primary design features of NERVE and review the method used to design and field-test NERVE.

\section{Primary Design Features}

NERVE is made up of three primary components: (a) a series of introductory screens that "frame the experience" according to one of the three universal principles of experiential learning (explained later in the paper), (b) a Learning Center which contains basic information on cranial nerve (CN) anatomy, physiology, symptoms, and pathology, and allows students to practice the use of relevant physical examination tools, and (c) an Exam Room that presents students with 10 cases of virtual patients presenting with $\mathrm{CN}$ disorders. To see and experience the entire system, we encourage you to access NERVE at http://nervesim.com, set up a free account, and take it for a test drive. We illustrate key design features of the Exam Room and Learning Center here to provide further context for answering the two research questions posed in this article.

Figure 1 illustrates how students may access the 12 VP cases contained in the NERVE Exam Room using either the menu-driven selection or the open-ended chat user interface.

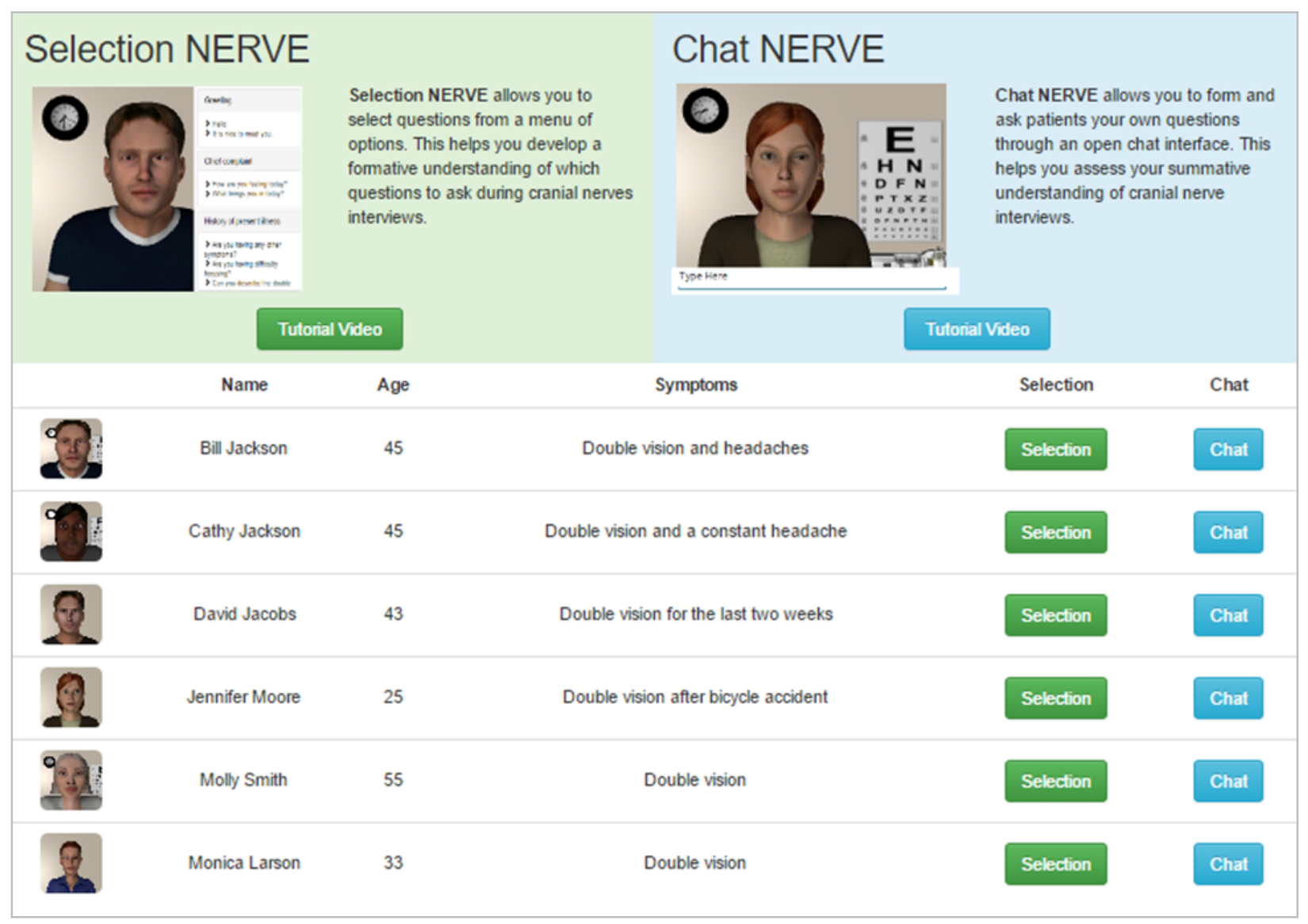

Figure 1. Screenshot of NERVE Exam Room providing access to virtual patients through two user interfaces. 


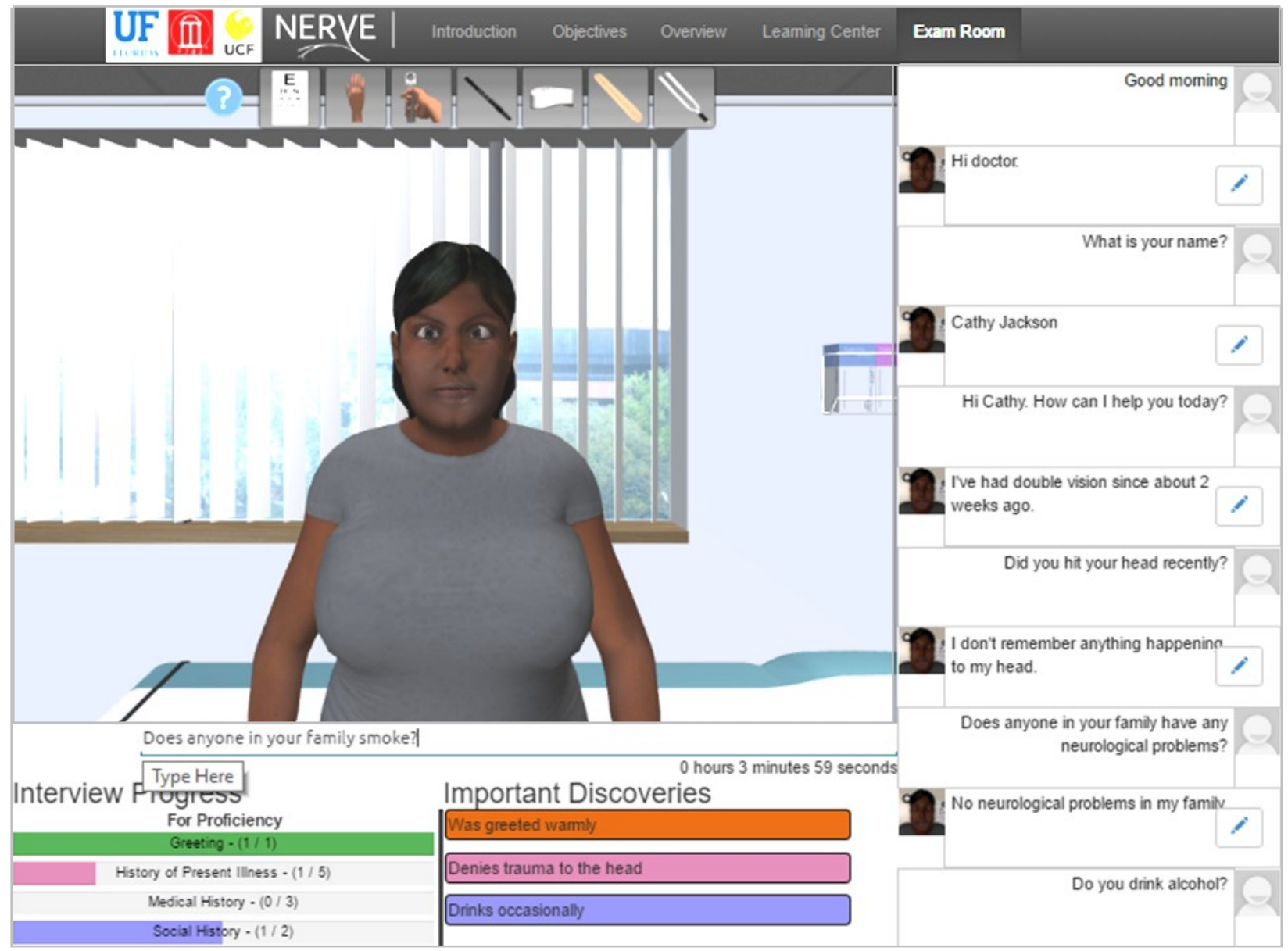

Figure 2. Screenshot of interactions with virtual patient using the open chat user interface.

Most VP simulations are based on a problemsolving (PS) approach, presenting learners with multiple -choice actions to advance through different scenes that depict various provider-patient interactions (Bearman, 2003; Huang, Reynolds \& Candler, 2007). However, by limiting responses to a defined set of choices, PS designs neither simulate authentic communications with patients, nor foster students' ability to formulate questions. The PS approach feels scripted and students have little control over what to do next (Bearman, 2003). To address the limitations associated with the problemsolving approach, we designed NERVE with an openended, chat-driven interface, further illustrated in Figure 2 , that allows students to interview the virtual patients following a relatively authentic, conversational narrative approach to uncover enough relevant information to make a diagnosis.

During the first several years of the project, students expressed significant concerns for the system's inability to recognize all forms of open-ended student input. The resulting feelings of frustration when the system did not respond in a meaningful fashion led us to develop a menu-driven user interface. The menu-driven interface presents all possible utterances recognizable by the virtual patient in a tree-like structure. During a virtual exam, a student navigates the tree by clicking on topic areas. Clicking on a topic expands that branch of the tree, revealing sub-topics and topic utterances. Selecting a question from the topic menu triggers a response from a database of possible patient utterances, as illustrated in Figure 3.

When we tested both chat and menu-driven interfaces during year four of the project, we found that some students preferred the realism of the open-chat interface, while others preferred the efficiency of the menudriven interface, and the majority wanted the option to use either or both interfaces. Considering that the system is designed for both first-year medical students, who may need more scaffolding and structure to develop interviewing skills, and second-year students who may need or want the freedom of the open-chat interface to work on their ability to formulate and organize interview questions, we decided to give students access to both the open-chat, and menu-driven user interface to interview, exam, and diagnose the virtual patients.

During the first four years of $R \& D$, prerequisite knowledge of basic cranial nerve anatomy, physiology, and pathology was covered by medical school faculty in conventional lecture style format before students were given access to NERVE. Following the typical medical school curriculum, first-year medical students were presented with content related to the anatomy and physiology of the central nervous system outside of brain stem (gross anatomy) and second year students were presented with content on neuro-anatomy and physiology 


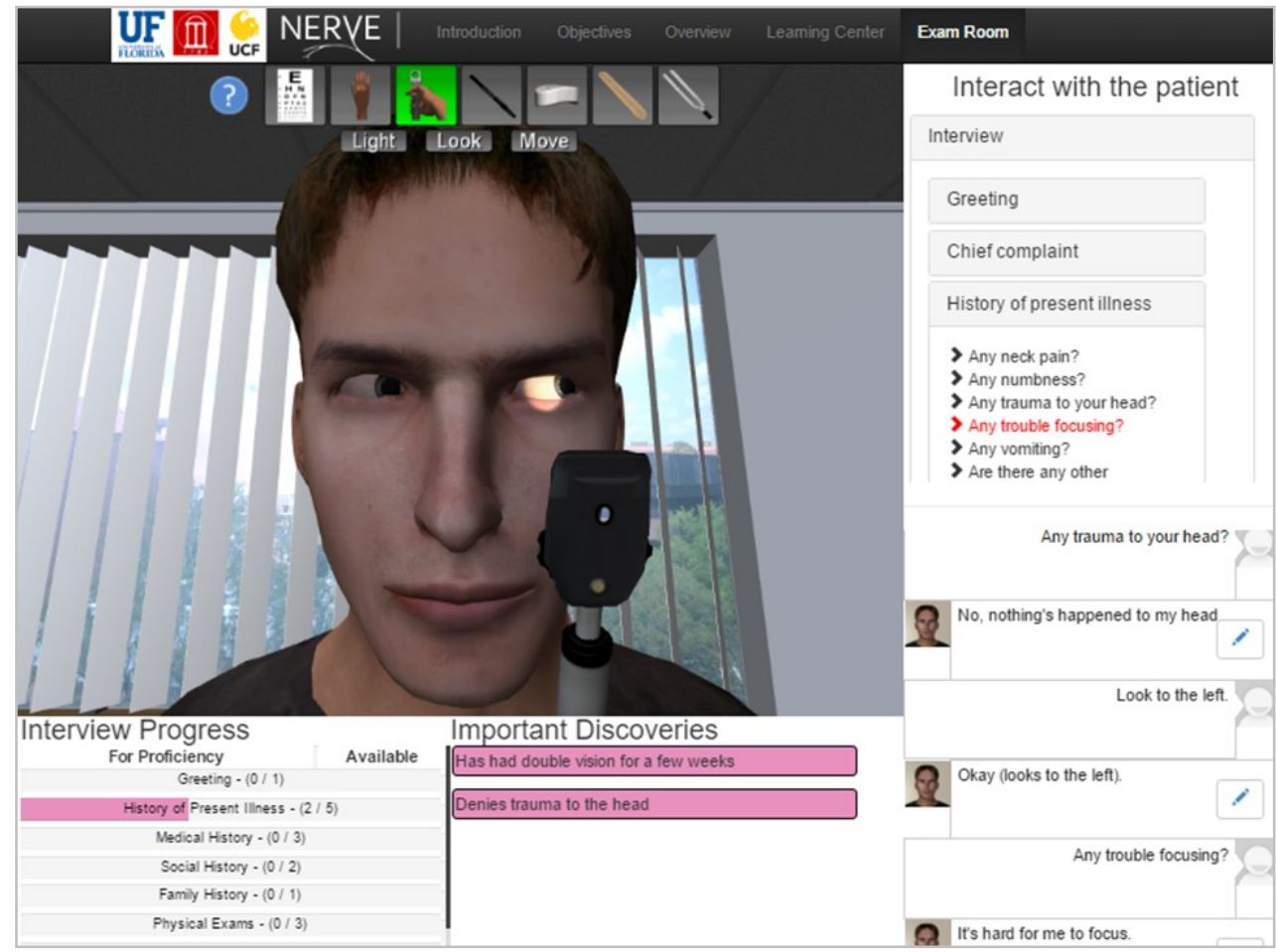

Figure 3. Screenshot of interactions with virtual patient using the menu-driven selection interface.

(inside the brain stem). The Learning Center represents a major addition to NERVE, made during the last year of the project. It helped make NERVE a self-contained, independent learning platform, giving students the opportunity to: (a) learn how and when to use the physical examination tools for diagnosing patients with potential $\mathrm{CN}$ disorders, (b) review relevant information about $\mathrm{CN}$ anatomy, physiology, symptoms and pathology, (c) explore published case studies about $\mathrm{CN}$ disorders, and (d) take a series of multiple choice quizzes. Figure 4 depicts the initial frame of the Learning Center that highlights key aspects of each of the 12 cranial nerves.

Selecting any one from the overview of all 12 cranial nerves provides access to further details about each nerve. Figure 5 illustrates how information about the anatomy and physiology of CN 1 (the Olfactory Nerve) is presented to students.

In addition to providing information about anatomy and physiology, symptoms and pathology, cases studies, and a quiz, the Learning Center also includes an Interactive Tool section for each CN. Figure 6 shows how the Interactive Tools provided for $\mathrm{CN} 4$ (the Trochlear nerve) allow students to use a slider to induce varying levels of trauma to the nerve and see the relative effects on the patient, as well as give students the opportunity to practice relevant physical examinations.

\section{Method}

To develop the latest version of NERVE that was made accessible to the general public in year 5, we conducted a series of design-based research studies during the final year of the project to formulate both theoretical insights and practical solutions with stakeholders in a real-world context, as suggested by McKenney and Reeves (2012). During the last year of R\&D, we worked with medical-school students, staff and instructors to address five features of design experiments posited by Cobb et al. 2003, p. 9-11), including: (a) the development of, "a class of theories about both the process of learning and the means that are designed to support that learning," (b) investigating, "the possibilities for educational improvement by bring about new forms of learning in order to study them," (c) testing a hypothesized learning process and fostering, "the emergence of other potential pathways," (d) being pragmatic in addressing practical problems faced by practitioners, and (e) containing iterative cycles of invention and revision. The design and development (Hirumi et al., 2016a) and the integration and testing of NERVE (Hirumi et al., 2016b) focused on investigating the possibilities of educational improvement, testing a hypothesized learning process, being pragmatic, and detailing the iterative cycles of invention and revision. For the purposes of the present article, we review the iterative design method followed during the last year, and discuss the development of a class of theories about learning and instructional design to examine the role of theory in informing design, and the role of testing in refining theory (Collins, 1992).

Like Hmelo and Day (1999), we gathered and analyzed computer logs and students' responses to the system throughout the final year of R\&D. We also completed two cycles of expert reviews, one-to-one and small group evaluations, along with a field test. During the first cycle, a subject matter expert (SME) and four second year medical students helped identify the most obvious errors in the initial alpha prototype of NERVE. The SME and students also evaluated the clarity of the instructional objectives, content information, and tutorials, and the usability of the user interface and physical exam tools. Comments and observations were recorded by two team members, who compiled the results, formulated and ranked recommended revisions based on 


\begin{tabular}{|c|c|c|c|}
\hline \\
\hline \multicolumn{4}{|c|}{ 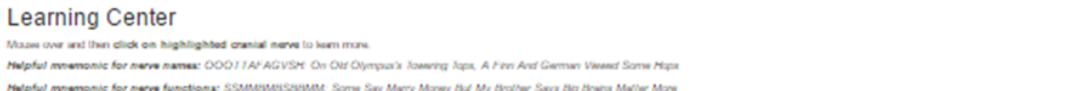 } \\
\hline$\frac{\text { Nenes }}{\text { Ont Orotiony }}$ & roes & Punction & Imerested Sinvoline \\
\hline coe cine & Semery & $\tan$ & man \\
\hline \multirow{2}{*}{ ca colmisar } & $\operatorname{Mas}$ & 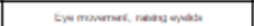 & 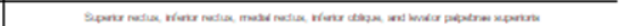 \\
\hline & Mrempentivas & amentand d th peqt & 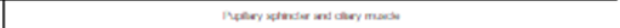 \\
\hline On trother & $\operatorname{mas}$ & 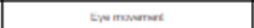 & Mast \\
\hline \multirow{2}{*}{ Ore trement } & $\operatorname{sen} x y$ & trax menasan & 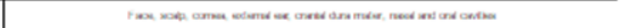 \\
\hline & $\operatorname{mas}$ & 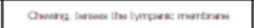 & 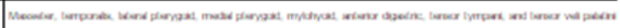 \\
\hline 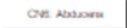 & $\operatorname{mas}$ & the moverant & Wentroctial \\
\hline \multirow{3}{*}{ over ras } & Sanery & lowe & 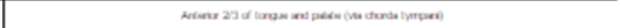 \\
\hline & $\operatorname{mata}$ & 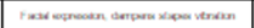 & 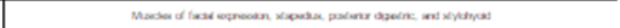 \\
\hline & Mresmentas & 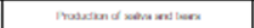 & 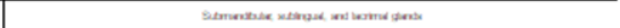 \\
\hline \multirow{2}{*}{ 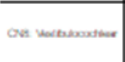 } & \multirow{2}{*}{ semery } & Manve & cothe \\
\hline & & Demox pquposian & 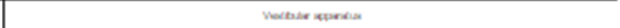 \\
\hline \multirow{4}{*}{ 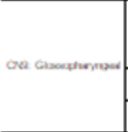 } & \multirow{2}{*}{ Sumery } & lowe & 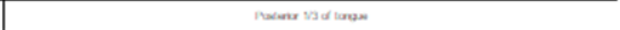 \\
\hline & & sumean & 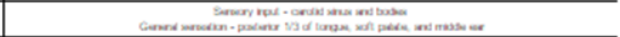 \\
\hline & $\operatorname{mas}$ & Smesuras & 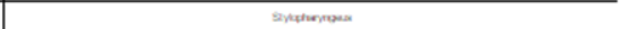 \\
\hline & Mrementinas & $\operatorname{sesen}$ & monatsent \\
\hline \multirow{4}{*}{ oweveveas } & \multirow{2}{*}{ sumar } & betw & 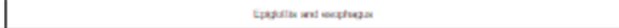 \\
\hline & & sumean & 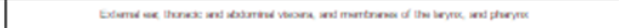 \\
\hline & Max & 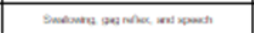 & 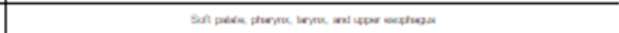 \\
\hline & Mresmpetsas & 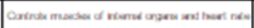 & 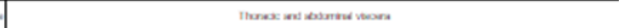 \\
\hline 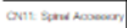 & $\operatorname{mas}$ & 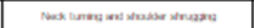 & 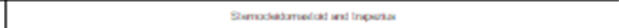 \\
\hline Ova2 Mnosined & $\operatorname{mag}$ & tanow monemat & 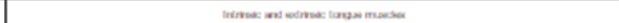 \\
\hline
\end{tabular}

Figure 4. Screenshot of the introductory frame of the NERVE Learning Center illustrating how information about twelve cranial nerves is initially presented to learners

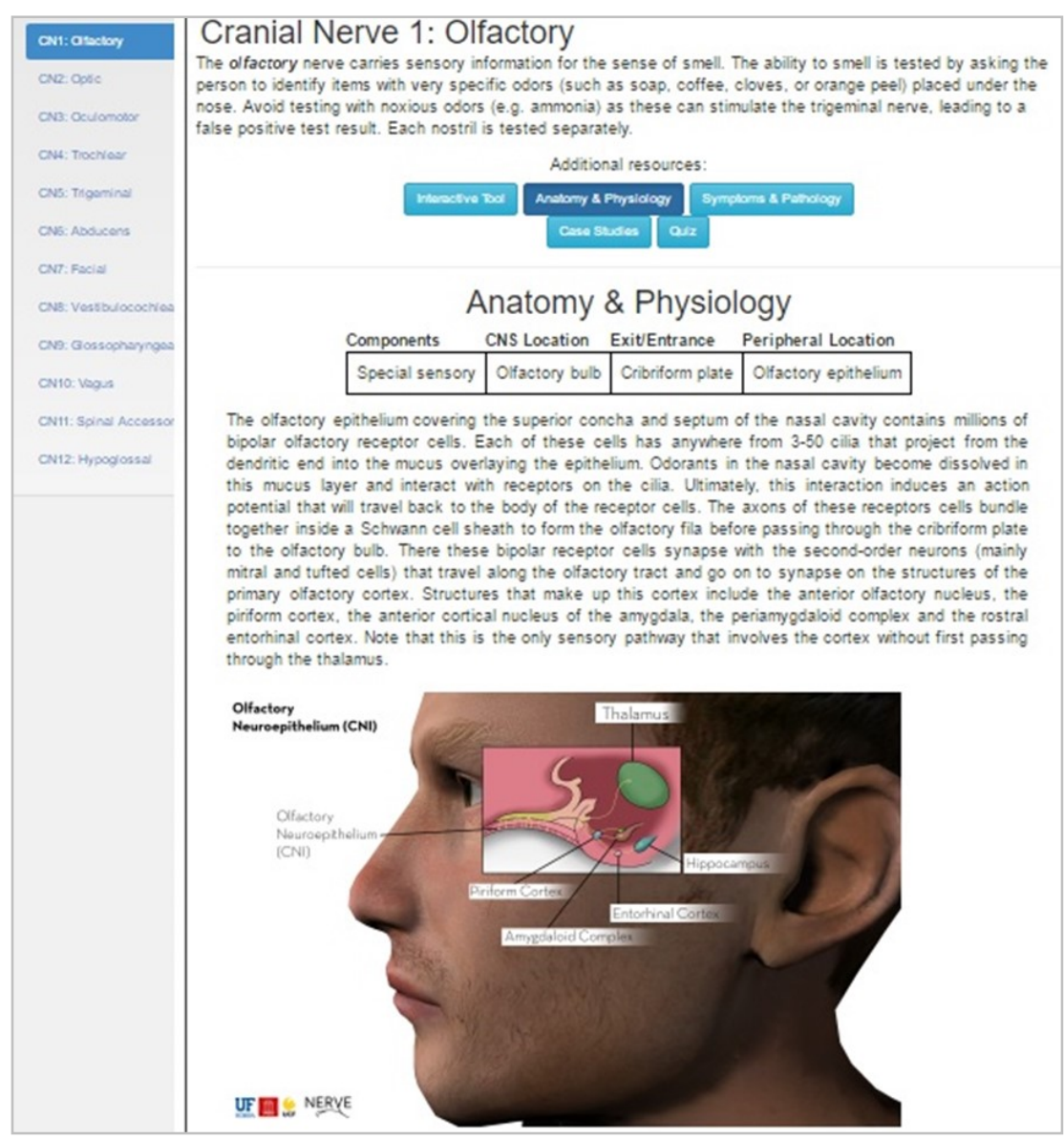

Figure 5. Screenshot illustrating how information on $\mathrm{CN}$ anatomy and physiology is presented to students 


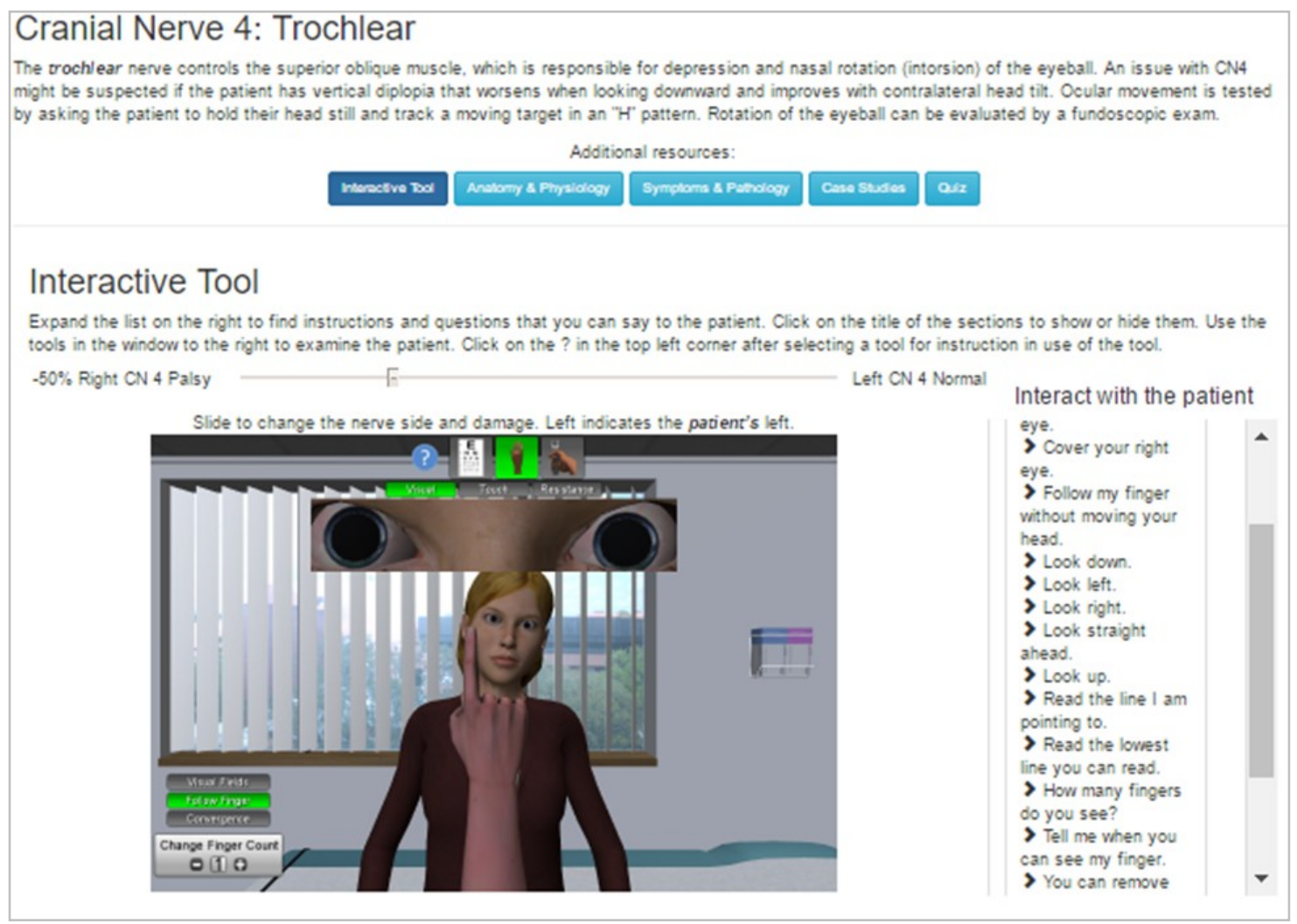

Figure 6. Screenshot depicting how students are given the opportunity to practice using relevant physical examination tools in the NERVE Learning Center

perceived impact and cost, and presented the recommended revisions to the entire $R \& D$ team. The entire R\&D team then discussed and reached consensus on what revisions to make and when during weekly teleconferences.

During the second cycle of design studies, two SMEs, four first year medical students, and a small group of instructional design graduate students evaluated version Two of the alpha prototype. The experts and students evaluated the revisions made based on the findings for Cycle One, and again reviewed the objectives, content, and tutorials for clarity and validity, and the interface and exam tools for usability. During the second cycle, the feasibility of implementing the VP simulation, given available time and resources, was also considered along with the impact of the VP simulation on students' attitudes and achievement. Again, the team members who facilitated the studies compiled the results, formulated and ranked recommended revisions, and presented their recommendations to the entire $R \& D$ team members, who then decided what revisions to make and when. Revisions based on Cycle Two findings led to the development and testing of the beta version of NERVE.

The beta prototype was field-tested with 120 medical students enrolled in a second-year neurology course as illustrated in Figure 7.

Patterned initially after Huwendiek et al.'s (2013) preferred sequencing of VPs and educational activities, we used existing VPs integration research, input received from the instructor, and the universal principles of experiential learning to hone our strategy for inte- grating NERVE into the medical school curriculum. The strategy included (a) a lecture on neurology, (b) a demonstration of NERVE with explicit expectations and requirements, (c) VPs interactions within NERVE, (d) an instructor-led after action review with the entire class, and (e) a standardized patient/virtual patient (SP/ VP) hybrid encounter, as depicted in Figure 7.

\section{Findings and Discussion}

We detailed the design and development of NERVE in Hirumi et al. (2016a) and report students' use, reactions, learning and transfer of NERVE in Hirumi et al. (2016b). Here, we focus on examining the pedagogical foundations of NERVE and answering the two design research questions specified for this article.

\section{Question 1: How were the principles of experiential learning and InterPLAY instructional theory used to design NERVE?}

The diversity of approaches for designing instructional stimulations in general, and VP simulations in particular is evident. But while some may lament the lack of consensus, we believe that studying alternative perspectives and fostering variance at this time may lead to innovation in a rapidly developing field. Inter$P L A Y$ in an instructional theory that integrates experiential learning principles with elements of story, play and game to optimize what other have referred to as instructional augmentation, support, and overlay for facilitating simulation-based learning. Here, we examine how we applied the InterPLAY instructional theory to design key pedagogical features of NERVE during the last year of research and development. 


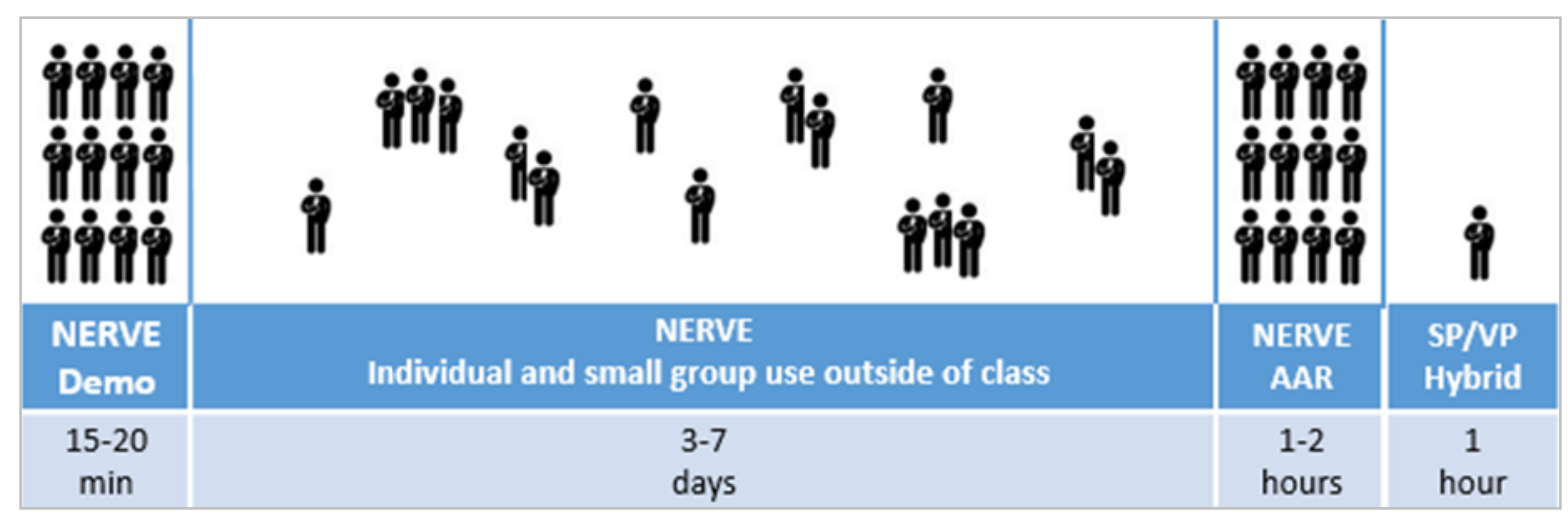

Figure 7. Figure depicting key events of the strategy used to integ rate the NERVE virtual patient simulation into medical school curriculum

Note. From "Advancing virtual patient simulations through design research and interPLAY: part II - integration and field test," by A. Hirumi et al., 2016, Educational Technology Research and Development, DOI 10.1007/s11423-016-9461-6. Copyright 2016 by

A. Hirumi. Reprinted with permission.

Experiential approaches to teaching and learning are based on two central principles posited originally by Dewey in 1920s and 30s: (a) continuity (the idea that students learned from their experiences), and (b) interaction (the notion that students' experiences were derived from their interactions with the environment and other individuals) (Dewey, 1938, p. 25). Advocates of experiential learning also believe that children, adolescents and adults learn best when presented with relevant, meaningful, and interesting challenges, and skill development and the learning of facts, concepts, procedures, and principles occur in context of how they will be used (Schank, Berman \& Macpherson, 1999). The merits of experiential learning are evidenced by the number of models that have been developed in its name over the past 50 years (e.g., Kolb \& Fry, 1975; Kolb, 1984; Schank, Berman \& Macpherson, 1999; Clark, 2008).

However, experiential approaches to teaching and learning do not explicitly address the role of human emotions and imagination during the learning process (Hirumi, 2013a). They neither explain how human emotions and imagination may affect experiential learning, nor suggest methods for stimulating human emotions and imagination during the learning process to enhance student engagement and achievement. As a result, the application of experiential learning principles may not realize the potential of emerging technologies to facilitate individual and team performance.

The InterPLAY instructional theory advances experiential learning by addressing the role of human emotions and imagination during the learning process. More specifically, InterPLAY integrates the elements of three primary conventions of interactive entertainment (i.e., Story, Play and Game) with existing experiential learning principles to evoke emotions, spark imagination, and create engaging and memorable learning experiences (Hirumi, 2013a, 2013b; Stapleton \& Hirumi, 2014, 2011).

Historically, human emotions and imagination have been ill-defined and hard to measure, making it difficult for educational researchers and practitioners to systemically address either construct in the development of learning theories and systems. Now, psychophysiological measures and neurobiological studies are providing meaningful insights into how emotions and imagination affect learning. Eliot and Hirumi (2015) present a critical review of research on human emotions and learning. Reyes and Hirumi (2015) review neuroscience research on methods used to stimulate and measure human imagination. Detailed discussion of the neurobiological dimensions of experiential learning, including human emotions and imagination are presented by Hirumi (2013a; 2013b) and discussed Atkinson \& Hirumi (2010).

Key findings from cognitive neuroscience studies of human emotions that drive InterPLAY are: (a) the strength of our emotional reactions to an experience determines how well and long we remember that experience (Labar \& Cabeza, 2006); (b) the valence of our emotional reactions (+ or -) determines whether we choose to return to or avoid similar experiences (Hare et al., 2005; Nieh, Kim, Namburi \& Tye, 2013); (c) the changing of emotions throughout an experience, in terms of both strength and valence, is what keeps us engaged with the experience over time (Li et al., 2014); and (d) physiological measures of basic human emotions (i.e., anger, fear, joy, sadness, disgust) may yield better predictors of human behavior than psychological measures of complex multi-dimensional conceptualizations of human emotions (Eliot \& Hirumi, 2015).

Findings from neurophysiological studies of human imagination that motivate InterPLAY suggest that (a) on-going emulations of cause and effect relationships mediate human behavior and decision-making (Colder, 2015); (b) imaging task performance enhances memory and our ability to complete the task (Borkin et al., 2013); and (c) if we can't imagine ourselves performing a task, our chances of engaging in and successfully completing the task are slim (Madan \& Singhal, 2014; Tia et al., 2010).

Figure 8 depicts the key concepts of InterPLAY and their related elements. In short, the theory posits the 
integration of story (characters, worlds, and events), play (stimulus, response, and consequences), and game (goals, rules and tools) with three principles of experiential learning described by Lindsey and Berger (2009) (i.e., framing, activating and reflecting on the experience) to enhance learner engagement, and the design of memorable and meaningful learning experiences. To answer research question one, we first describe how we applied the three principles of experiential learning to design NERVE. We then discuss how we applied the conventions of story, play and game to advance experiential learning and the design of the VP simulation.

Applying Principles of Experiential Learning, In 2012, the Principal Investigators (PIs) of NERVE suggested that interactions with virtual patients can leverage experiential learning theory to motivate learners, and referenced Kolb and Fry's (1975) four-stage cyclical model as a strategy for students to become more active participants in the learning process (Cendan \& Lok, 2012). Since then, no further references or explicit attempts were made to address experiential learning principles until the last year of the project.

During the first three to four years of the initiative, team members focused on examining tools and techniques used to interview, examine and diagnose patients presenting with $\mathrm{CN}$ disorders. In essence, they formulated a model of clinical reasoning to help drive the design of the VP simulation. The need to adequately represent the visual and communicative effects of the injuries drove the team to create authentic representations of $\mathrm{CN}$ palsies and study different ways to optimize simulated interactions with VPs.

Entering the final two years of the project, the team began to consider the design and delivery of the final product. The original grant proposal called for the development of a virtual environment that enables medical students to rehearse interviewing, examination, and diagnostic skills. The team also wanted to produce a stand-alone product - a system that students (with some direction) could access on their own to gain basic skills and knowledge about CNs and diagnosing patients with $\mathrm{CN}$ disorders so that medical educators could spend

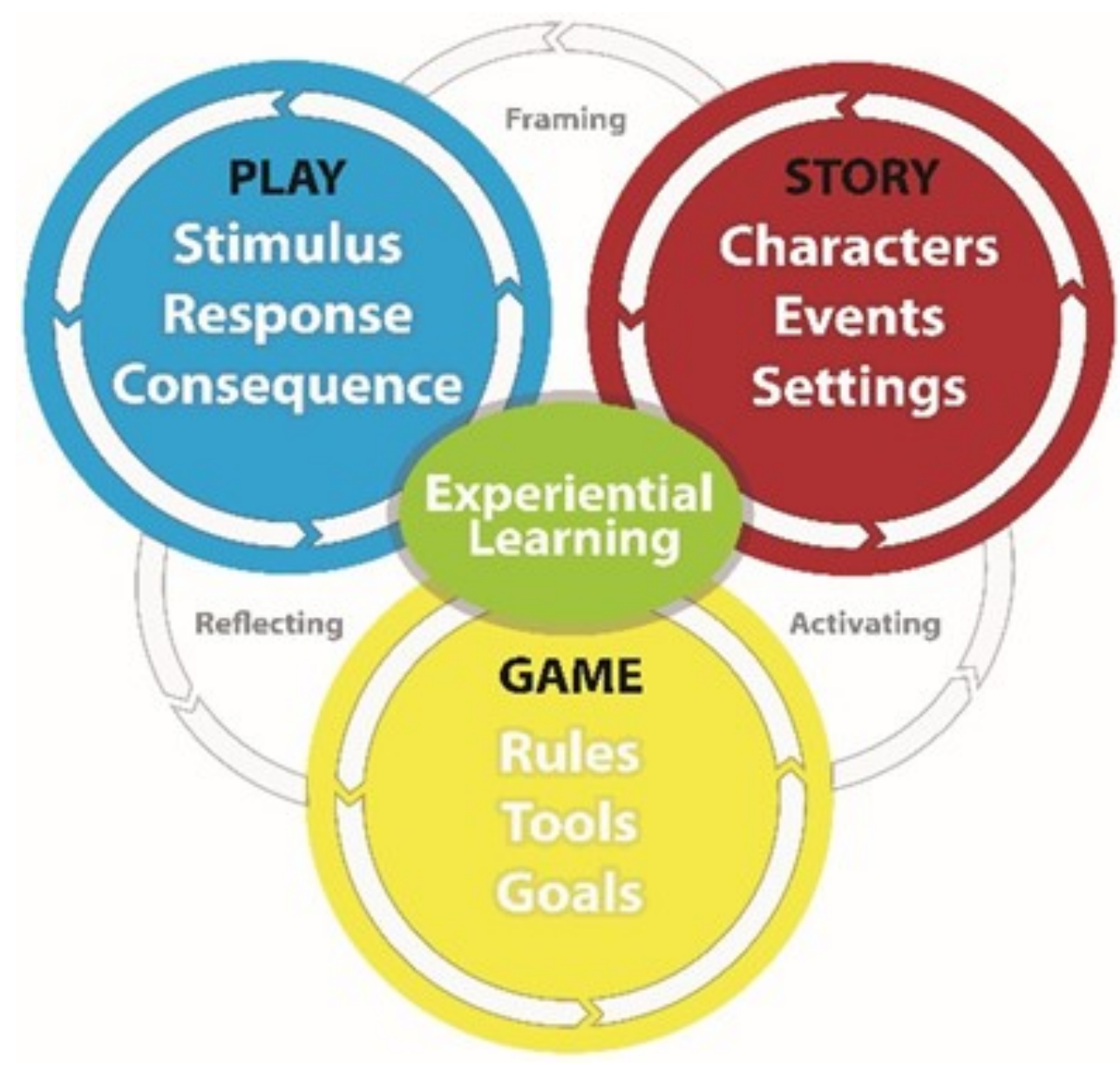

Figure 8. Conceptual elements of the InterPLAY Instructional Theory.

Note. From "Advancing virtual patient simulations through design research and interPLAY: part II integration and field test," by A. Hirumi et al., 2016, Educational Technology Research and Development, DOI 10.1007/s11423-016-9461-6. Copyright 2016 by A. Hirumi. Reprinted with permis- 
more precious time in class addressing clinical variations or other curricular issues. For over three years, the team experimented with different tools and techniques, and gained insights on how to simulate $\mathrm{CN}$ palsies and the interview/examination process.

Tasked with helping design a standalone system, the instructional design (ID) expert refocused the team's attention on the pedagogical foundations of NERVE. He characterized the evolution of experiential learning theory, briefed team members on published experiential approaches, and encouraged team members to apply the three universal principles of experiential learning described by Lindsey and Berger (2009) during the last year of R\&D. He chose to focus on the three experiential learning principles for two reasons: (a) the team adopted experiential learning as a foundation for design earlier in the design process (Cendan \& Lok, 2012); and (b) applying a smaller, parsimonious set of principles seemed more feasible than addressing larger sets, such as Bergin and For's (2003) twelve pedagogical features for designing ISPs.

When the potential for improving NERVE became apparent, the R\&D team adopted and worked to apply the three universal principles. It became evident that the team was already applying Principle 2 . Principles 1 and 3 were not previously addressed and became particularly important for integrating key instructional events before and after the VP simulations to facilitate learning.

Principle 1 - Framing the Experience. To frame the experience, Principle 1 includes, "communicating the instructional objectives, assessment criteria, expected behaviors, and social structure with peers, instructors and the environment beyond the class" (Lindsey \& Berger, 2009, p. 124). During the initial four years of R\&D, objectives varied based on goals of the researchers and the specific study under investigation. For our project, an explicit set of measurable performance objectives for medical students were specified for NERVE during the final year of development.

Application of Principle 1 informed an important discussion between those involved in technical/ computing development and those responsible for the medical content. In short, they had to agree on the core outcomes to be presented and assessed. The team had to strategize how much simulation was enough to demonstrate certain pathologies; for example, after early attempts to incorporate haptic (force) feedback, no effort was made to simulate examination tools and techniques that required a sense of touch or motor perception to limit the scope of the simulation. The learning objectives had to be met with the understanding that there would be reasonable technical boundaries for the modeling and simulation of the palsies.

Cognitive task analysis of the goal (to give medical students a standardized experience in examining, interviewing, and differentially diagnosing patients with $\mathrm{CN}$ palsies) revealed essential subordinate skills and knowledge that were transformed into performance objectives (such as to recognize the pathology and symptoms of cranial nerve dysfunctions, perform appropriate physical examinations, identify damaged nerves, and formulate hypotheses about the cases of identified pal- sies) and made explicit in the introductory screens of NERVE during the last year of R\&D. The recommended social structure, also communicated with the initial introductory screens, encourages students to explore NERVE individually or "learn best by working in teams of two or more students" as suggested by earlier research findings (Rivera-Gutierrez et al., 2014, p. 697). To further frame the experience, students are shown the two basic components of NERVE, a Learning Center (where they can practice the use of physical examination tools and learn about cranial nerve anatomy, physiology, symptoms and pathology) and the Exam Room (where they are tasked with diagnosing virtual patients presenting with symptoms of $\mathrm{CN}$ disorders). The initial pages also mention the benefits of the experience learning, practice, and a safe place to explore - to frame what students should gain from the experience. In reality, much of what has become nervesim.com is related to framing the experience.

However, the assessment criteria and expected behaviors were left to the instructor to define and communicate when the system is first demonstrated to students. Performance assessments in the form of quizzes and students' diagnoses of virtual patient cases are included in NERVE, but the system does not specify requirements for examining specific $\mathrm{CNs}$ and patients and completing certain quizzes so faculty at different medical schools may establish performance criteria and expectations for their own students.

Like others (c.f., Lindsey \& Berger, 2009), we believe that framing the experience is important. However, until we conducted multiple studies focused on the usability and implementation of the system, team members thought the experience was adequately framed, but in reality, we found out during testing that users were still confused as to what exactly they were to be learning from the experience. NERVE was simply an application that was run to interact with a virtual patient with a particular cranial nerve disorder. The nervesim.com website now frames these experience and provides a way for an individual to learn without the direct assistance of an instructor (although instructors are certainly part of the overall process).

Principle 2 - Activating Experience. To activate both prior and newly initiated experiences, Principle 2 recommends: (a) providing authentic experiences to facilitate transfer; (b) making decisions that have authentic outcomes; (c) orienting learners so they see the relevance of the specific learning activities in relation to the larger problem; and (d) presenting challenges with optimal levels of difficulty to keep them engaged (Lindsey \& Berger, 2009).

Principle 2 was the initial driver for the project that was most consistently addressed prior to formally adopting the three universal principles of experiential learning. From the beginning of the project, team members constantly sought to facilitate transfer by providing the most authentic experiences possible with VP simulations that ask learners to make decisions that have realistic outcomes. Throughout the five-year project, team members also sought to orient learners so they could see the relevance of the VP simulations in relation to the problem of interviewing, examining and diagnosing patients with $\mathrm{CN}$ disorders, and to present cases 
with optimal levels of difficulty to keep medical students engaged.

For the final year of development, we reexamined each tool and the user interface for authenticity and ease of use, making a few significant changes. For example, in previous versions of NERVE, students performed a funduscopic examination by moving a virtual ophthalmoscope towards the patient's eye, which showed the entire retina. Simply moving the virtual ophthalmoscope, however, did not match well with the real examination. We simplified the interface so that with a couple of clicks, students could perform all the actions necessary to complete the physical examination with an ophthalmoscope (e.g. moving the ophthalmoscope to a particular eye, turning on the light, and maneuvering it to examine the retina). Other tools that were streamlined by automating their use included a hand (to test eye tracking), eye chart, tongue depressor, tuning fork, bar of soap, and a ballpoint pen.

Case histories were also generated and made accessible for each VP that oriented learners to the specific learning activities within context of a larger problem being experienced by the patient. To provide optimal levels of difficulty, students were encouraged to use either the open chat or the closed menu interface to examine and interview the virtual patients based on their level of experience.

Principle 3 - Reflecting on Experience. Principle 3 suggests that, "Experience must be analyzed to learn from it. Reflection should involve students answering the questions, "What happened?" "Why did it happen?" "What did I learn?" and "How would I apply this knowledge to future experiences?" (Lindsey \& Berger, 2009, p. 129).

Prior to the final year of development, the R\&D team conducted one study that examined the effects of student reflections during the learning process (RiveraGutierrez et al., 2014). Students were prompted with questions to reflect on specific topics, actions or responses during specified interactions. Three raters appraised the learners' responses according to a scale developed by Mezirow (1990). Results showed that 58\% of the learners demonstrated evidence of reflection in at least one of the reflective moments. Critical reflection was harder to achieve; only one learner showed critical reflection in her response. Given that the interactions were limited to 20 minutes (including answering the reflective prompts) in this prior study, we felt that meaningful reflections would increase if time constraints were removed. So we made reflective learning a formal part of NERVE during the last year of R\&D.

To address Principle 3, we planned and implemented an AAR for the field test of the beta prototype based on strategies recommended by Salem-Schatz, Ordin and Mittman (2010). In short, we followed guidelines for planning and conducting an AAR, including allocating time, organizing the discussion by issues, introducing and "setting up" the AAR prior to using NERVE, presenting and following ground rules, asking key questions (i.e., What went well and why? What can be improved and how?), and following facilitator tips. We did ask an additional question at the beginning of the AAR; namely, what did you learn from the system? We added the additional question to enable the instructor to diagnose and correct misconceptions, fill in gaps, and elaborate on key points.

As a recognized component of best practice, we prescribed an AAR to address Principle 3 when integrating NERVE into the curriculum. However, we have yet to fully develop the possibilities of AARs, primarily because students are not asked to complete an AAR in other learning exercises. Introducing an AAR as a specific step in learning after interacting with NERVE led to an additional process for the students. With no prior recognition of its importance, and no equivalent followup, the AAR and application of Principle 3 lived in a vacuum. To realize its potential, we need to consider how to better apply Principle 3 within and after the use of NERVE as well as how to facilitate AARs across the curriculum.

Applying the Conventions of Story, Game and Play. One of the primary reasons we adopted InterPLAY to guide the design and development of NERVE was the separation of the game and play components of the theory. The distinction made between game and play clearly illustrated the role of the VP simulations in the NERVE Exam Room (that enable students to test and refine their diagnostic skills) and $\mathrm{CN}$ content information provided in the NERVE Learning Center (that learners may want or need to inform the diagnostic process).

As we noted earlier when we described the application of experiential learning principles, Principle 2 Activating the Experience was the initial, primary driver for the project that led to the development and experimentation of the VP simulations throughout the fiveyear project. During the last year of R\&D, the virtual patients presented to learners in the NERVE Exam Room represented the game component of the InterPLAY theory, presenting students with authentic, simulated experiences to test and refine their diagnostic skills with specific goals, rules and tools.

During the first four years of $\mathrm{R} \& \mathrm{D}$, prerequisite knowledge of basic cranial nerve anatomy, physiology, and pathology were taught by medical-school faculty in a conventional lecture-style format before students were given access to NERVE. InterPLAY illustrated how the addition of content information to the system could enable NERVE to become an independent learning platform that medical schools and students could use to cover both the acquisition and application of relevant $\mathrm{CN}$ skills and knowledge.

With the adoption of InterPLAY, we added a Learning Center to NERVE during the final year of the project that gave students the opportunity to: (a) learn how and when to use the physical examination tools for diagnosing patients with potential $\mathrm{CN}$ disorders, (b) review relevant information about $\mathrm{CN}$ anatomy, physiology, symptoms and pathology, (c) explore published case studies about $\mathrm{CN}$ disorders, and (d) take multiplechoice quizzes about each $\mathrm{CN}$ to help them self-assess and monitor their own knowledge acquisition. A link allowed students to access the Learning Center at any time; before, during and/or after interacting with the VP cases in the Exam Room. 
The addition of the Learning Center also made NERVE complete from a student's perspective. After making a mistake, students can find it very frustrating to hunt for a reliable source of information to correct the misunderstanding. This is especially true in medicine where misinformation is easily available and where reliable texts on specific topics can be too in-depth or difficult to understand. The Learning Center serves as an easily accessible, easy to understand resource that can be used both to teach the information and as a quick reference for students to reinforce knowledge and correct errors in knowledge.

As much as the distinction between game and play led to the addition of the NERVE Learning Center to the VP stimulations in the NERVE Exam Room, we did relatively little to formulate a story and apply story elements to NERVE. The team felt that, with limited time and resources, priority had to be placed on creating the Learning Center. Each character has a back story that is portrayed in real time during the interactions with the VP. Otherwise, the use of story is limited to text-based case histories, pictures and simulated interactions of each VP in the exam room, and an AAR at the end of the experience that encourages reflection and the sharing of students own experiences with NERVE to enhance learning, retention and transfer.

Question 2 - How did design and testing of NERVE advance experiential learning principles and the InterPLAY instructional theory?

We detailed the design and development of NERVE, including findings from the two iterative cycles of design studies and improvements made to NERVE based on the findings in Hirumi et al. (2016a). We also reported the results of implementing and field-testing NERVE, including data on students' use, reactions, learning and transfer in Hirumi et al. (2016b). To answer the second research question posed in this article, we discuss specific findings from the design, development, testing and implementation of NERVE that led to recommended refinements to universal principles of experiential learning posited by Lindsey and Berger (2009), and the InterPLAY instructional theory.

Recommended refinements to the principles of experiential learning. The primary recommendations for refining the universal principles posited by Lindsey and Berger (2009) revolve around Principle 3 - Reflecting on the Experience. Specifically, based on field-test data, team members felt that Principle 3 could be improved by expanding on the questions, and by providing both examples and non-examples of the responses sought during the After-Action-Review (AAR).

To reflect on the learning experience, Lindsey and Berger (2009) suggest asking four fundamental questions: What happened? Why did it happen? What have I learned? How would I apply this knowledge of future experiences? (p. 129). As we applied Principle 3, we decided to use alternative questions recommended for facilitating AARs for reasons noted earlier. In short, we asked students to reflect on what they learned, what experiences and resources they found useful, and what they thought should be done to improve NERVE and the learning experience during the prescribed AAR.
Based on students' reflections reported during the AAR, we recommend two specific refinements to Principle 3 as described by Lindsey and Berger (2009). The first improvement is to puts the onus on the students to take advantage of the opportunity to learn using NERVE. Specifically, asking the students "what steps could you take to improve your own learning using NERVE?" NERVE is not a perfect system with $100 \%$ recognition of questions asked of the virtual patients (VPs). What we continually encountered throughout the project was that when system problems occurred (e.g., incorrect or no responses from the VPs), students became frustrated and lost motivation. We suggest that if the students were asked to look past the system's limitations and identify specific ways that they could make better use of the system to improve their own learning, their reflections and the application of Principle 3 would lead to more meaning and useful results.

The second recommended refinement to Principle 3 is to prescribe examples and non-examples of desired responses to the reflective questions. During the AAR, we found that many students would immediately begin to identify problems with the system and provide recommendations for improvement even though they were prompted to reserve such comments for the last part of the AAR. Apparently, students were eager to vent. As soon as we noted the problem, we highlighted nonexamples given by students as well as gave several proper examples, and soon found that students were able to provide appropriate responses to the question, "What did you learn?" Following suit, we verbally presented students with good examples of what we were looking for in response to what was useful and what could be improved, which appeared to prevent issues with the nature of students' reflections.

Advancing InterPLAY. Application of the three conventions of interactive entertainment (ie., story, play and game) facilitates six instructional events that form the InterPLAY instructional strategy. Figure 9 illustrates how insights gained during the design of NERVE advanced the strategy. Prior to NERVE, Inter $P L A Y$ was conceived to facilitate the six events in a relatively linear fashion as illustrated in Figure 9A (Stapleton \& Hirumi, 2014). Learners were first exposed to a story to capture their attention by answering the question, "Why should I care?" The story would then naturally drive learners through cycles of inquiry and discovery to acquire the fundamental skills and knowledge associated with the desired outcome(s), that would then propel them to apply what they learned to create and experiment with different solutions to beat the game. At the end, students would then be asked to share their story of what they learned to complete the InterPLAY experience.

While applying InterPLAY instructional strategy to NERVE, it became apparent that learners may neither need nor want to review resources posted in the Learning Center before attempting to diagnose the cases in the Exam Room. Like most gamers, they may only want to look up supporting information if they get stuck and have difficulties beating the game. Similarly, some medical students may want to first go to VP simulations to create and experiment with different solutions to the cases and only PLAY with various educational re- 


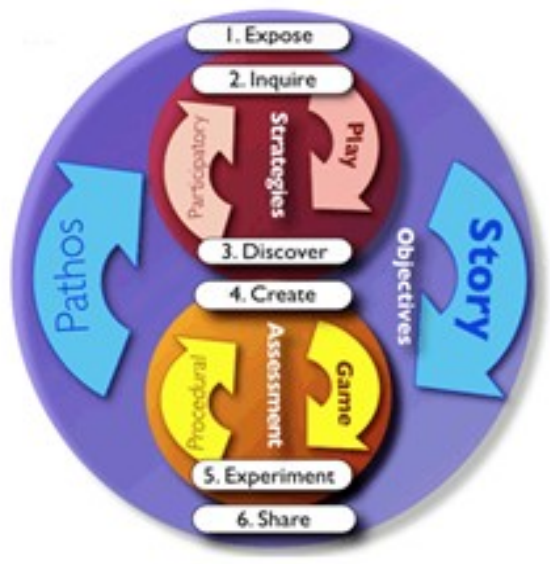

A. Original conceptualization of the InterPLAY instructional strategy

sources to inquire and discover key facts and information about $\mathrm{CN}$ anatomy, physiology, symptoms and pathology when needed. Others may want to inquire about and discover information about $\mathrm{CN}$ anatomy, physiology, symptoms and pathology, and practice using the physical examination tools in the Learning Center before venturing to experiment with the VPs in the Exam Room. Figure 9B depicts that latest version of the strategy based on insights gained from the design of NERVE that indicates that learners may PLAY with learning resources before, during or after they attempt to solve problems and overcome authentic challenges posed by the system. Allowing students to access learning resources at any time during the simulation is particularly helpful in sustaining the motivation and positive emotions of expert learners that would otherwise feel frustrated by having to review information they feel they have mastered. Providing access to important facts, concepts, rules and principles within the context of how they are to be used as learners work to overcome authentic problems is also more consistent with experiential learning principles.

\section{Concluding Thoughts and Reflections}

The last year of R\&D demonstrated the interactive nature of applied and basic research. We emphasized the role of theory in informing design, and used testing to refine theory. Specifically, we applied three universal principles of experiential learning and the InterPLAY instructional theory to guide the design of NERVE, and the design and testing of NERVE advanced the InterPLAY theory by revealing recommendations for improving the principles.

From the beginning, software engineers and medical experts focused on activating the experience (Principle 2). Application of Principle 1 (Framing the Experience) and 3 (Reflecting on the Experience) resulted in the design of key instructional events presented before and after interactions with the VP simulations. The separation of game and play distinguished the role of

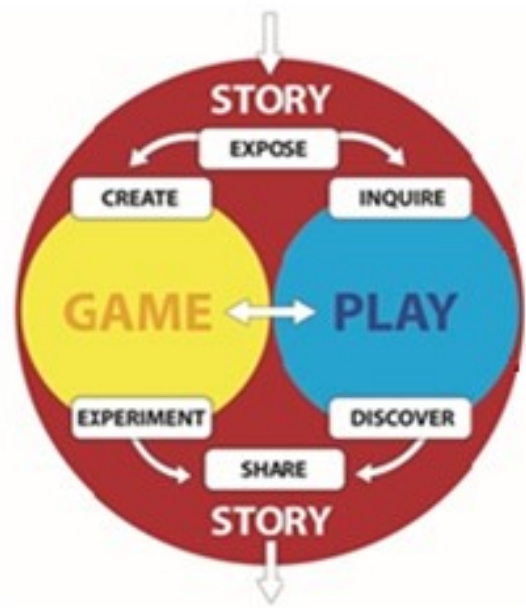

B. New conceptualization of the InterPLAY instructional strategy

knowledge acquisition versus knowledge application in clinical reasoning that led to the development of the NERVE Learning Center.

In turn, the design and testing of NERVE, including expert reviews, one-to-one and small group evaluations, and field testing led to improvements to the InterPLAY instructional theory and recommended refinements to the principles of experiential learning. We learned that it may be better to give learners direct access to the simulations (aka game) and allow them to "play" with the content information to acquire fundamental skills and knowledge when needed or desired, rather than to require them to go through basic content information first and then use the simulations to diagnose patients, as the theory originally prescribed.

The team believes that story and game aspects of NERVE could be greatly enhanced. We looked at designing vignettes within scripts to help students understand patient concerns better. More time and effort could also be placed on formulating a plot that better ties the VPs encountered in the exam room together to increase empathy, interest and engagement. More resources could also be directed toward advancing the game component of the system. In earlier experiments with NERVE, we explored the use of leader boards that identified students earning highest points for their diagnoses, and the creation of avatars for students to establish their own presence as game elements that appeared to have potential. None of these story and game features are presently in nervesim.com, though we think some would probably increase learner engagement and voluntary time-on-task. In conclusion, reflections by the Principal Investigator and Chief Engineer may best capture the essence of the final year of R\&D and the application of learning principles and instructional theory:

NERVE used the InterPLAY theory [including the 3 principles of experiential learning, and the elements of story, play and game] to transition from a standalone simulation where users were expected to use 
the system to demonstrate knowledge acquisition, to a system that provided motivation, learning, and evaluation. The resulting experience impacted students, faculty, students, and researchers. The InterPLAY-driven version of NERVE was evident to faculty on how they would use the system in their classroom. Because the system now more clearly positioned itself in the curriculum, faculty's evaluation of the system went from how to use NERVE to when and where to use NERVE. Students were able to develop expectations both of the software and their performance in NERVE due to the Game and Play components. Finally, researchers were provided a blueprint of how to develop simulation, education, and instructional design as to have end users more quickly identify benefits and consider adoption.

\section{Author Notes:}

Research reported in this paper was supported by the National Institutes of Health $(\mathrm{NIH})$ under award number 1R01LM010813-01. The content is solely the responsibility of the authors and does not necessarily represent the official views of the National Institutes of Health.

Correspondence concerning this article should be addressed to Atsusi Author, Instructional Design \& Technology Program, Department of Education and Human Sciences, University of Central Florida, Orlando, FL 32816. Contact: atsusi.hirumi@ucf.edu.

\section{References}

Agency for Healthcare Research and Quality (AHRQ) (2013). PAR-11-024 Advances in patient safety through simulation research. http://grants.nih.gov/ grants/guide/pa-files/PAR-11-024.html. Accessed January 20.

Atkinson, T. \& Hirumi, A. (2010). The Game Brain: What does the brain tell us about playing games in schools? In A. Author (Ed.). Playing Games in School: Using Simulations and Videogames for Primary and Secondary Education (pp. 57-73). Eugene, WA: International Society for Technology in Education.

Bearman, M. (2003). Is virtual the same as real? Medical students' experiences of a virtual patient. $\mathrm{Aca}$ demic Medicine, 78(5), 538-545.

Bergin, R. A., \& Fors, U. G. H. (2003). Interactive simulated patient: An advanced tool for studentactivated learning in medicine and healthcare. Computers \& Education, 40(4), 361-376

Berman, N., Fall, L., Smith, S., Levine, D. A., Maloney, C. G., Potts, M., et al. (2009). Integration strategies for using virtual patients in clinical clerkships. Academic Medicine, 84(7), 943-949.

Borkin, M. A., Vo, A. A., Bylinskii, Z., Isola, P., Sunkavalli, S., Oliva, A., \& Pfister, H. (2013). What makes a visualization memorable? IEEE
Transactions on Visualization and Computer Graphics, 19(12), 2306-2315.

Cendan, J., Lok, B. (2012). The use of virtual patients in medical school curricula. Advances in Physiology Education. 36(1), 48-53.

Clark, R. (2008). Design document for a guided experiential learning course. TRADOC DAAD 19-99-D0046-0004. The Institute for Creative Technologies and the Rossier School of Education, University of Southern California

Cobb, P., Confrey, J., diSessa, A., Lehrer, R., Schauble, L. (2003). Design experiments in educational research. Educational Researcher, 32(1): 9-13.

Colder, B. (2015). The basal ganglia select the expected sensory input used for predictive coding. Frontiers in Computational Neuroscience. 9:119. doi: 10.3389/fncom.2015.00119.

Collins A. (1992). Toward a design science of education. In Scanlon E, O’Shea T, eds. New Directions in Educational Technology. Berlin: SpringerVerlag, 15-22.

Cook, D. A., Erwin, P. J., \& Triola, M. M. (2010). Computerized virtual patients in health professions education: A systematic review and meta-analysis. Academic Medicine. 85:15890-1602.

Consorti, F., Mancuso, R., Nocioni, M., \& Piccolo, A. (2012). Efficacy of virtual patients in medical education: a meta-analysis of randomized studies. Computers \& Education, 59(3), 1001-1008.

de Jong, T., \& von Joolingen, W. R. (1998). Scientific discovery learning with computer simulations of conceptual domains. Review of Educational Research, 68(3), 179-201.

Dewey, J. (1938). Logic: The Theory of Inquiry. New York, NY: Holt, Rinehart and Winston.

Eder-Van Hook, J. (2004). Building a National A genda for Simulation-based Medical Education. Retrieved 27 September 2014 from http://www.medsim.org/ articles/AIMS 2004 Report Simulationbased_Medical Training.pdf.

Eliot, S. A., \& Hirumi, A. (2015). The elusive construct of emotions: An interdisciplinary critical literature review. Concurrent session presented the annual Association for Educational Communication and Technology conference, Indianapolis, IN. Nov. 4-6.

Fischer, M., Hege, I., Hörnlein, A., Puppe, F., Tönshoff, B., \& Huwendiek, S. (2007). Virtual patients in medical education: a comparison of various strategies for curricular integration. Zeitschrift fur Evidenz, Fortbildung und Qualitat im Gesundheitswesen, 102(10), 648-653.

Gibbons, A. S., McConkie, M., Seo, K. K., \& Wiley, D. A. (2009). Simulation approach to instruction. In C. M. Reigeluth \& A. A. Carr-Chellman (Eds.). Instructional-Design Theories and Models: Building a Common Knowledge Base (Volume III, pp. 167193). New York, NY: Routledge. 
Gredler, M. E. (2004). Games and simulations and their relations to learning. In D. H. Jonassen (Ed.), Handbook of research on educational communications and technology ( $2^{\text {nd }}$ ed., pp. 571-583). Mahwah, NJ: Erlbaum.

Hare, T. A., Tottenham, N., Davidson, M.C., Glover, G. H., Casey, B. J. (2005). "Contributions of amygdala and striatal activity in emotion regulation." Biological Psychiatry, 57(6), 624-632.

Hmelo, C., \& Day, R. (1999). Contextualized questioning to scaffold learning from simulations. Computers \& Education, 32(2), 151-164.

Huang, G., Reynolds, R., \& Candler, C. (2007). Virtual patient simulation at US and Canadian medical schools. A cademic Medicine, 82(5), 446-451.

Huwendiek, S., Duncker, C., Reichert, F., De Leng, B. A., Dolmans, D., van der Vleuten, C. P., \& Tönshoff, B. (2013). Learner preferences regarding integrating, sequencing and aligning virtual patients with Advancing virtual patient simulations through design other activities in the undergraduate medical curriculum: A focus group study. Medical Teacher, 35(11), 920-929.

Huwendiek, S., Reichert, F., Bosse, H. M., De Leng, B. A., Van Der Vleuten, C. P., Haag, M., . Tönshoff, B. (2009). Design principles for virtual patients: a focus group study among students. Medical Education, 43(6), 580-588.

Hirumi, A. (2014). Advancing Virtual Patient Simulations with InterPLAY: Examining the Role of ID Principles and Practices. Concurrent Session presented the annual Association for Educational Communication and Technology conference, Jacksonville, FL. Nov. 5-9.

Hirumi, A. (2013a). Gamifying Virtual Patient Interactions with InterPLAY: A Grounded Approach to Medical Simulation Research \& Development. Invited keynote speech presented at the 1st International and $6^{\text {th }}$ National Congress of e-Learning in Medical Sciences; October 23-25, Shiraz, Iran.

Hirumi, A. (2013b). InterPLA Y to Foster Innovation and Creativity. Invited keynote speech presented at the $8^{\text {th }}$ International Congress on Learning Technologies; October 29-31, Guadalajara, MX.

Hirumi, A., Johnson, T. \& Reyes, R. (2015). FieldTesting Strategies to Improve the Integration of Virtual Patient Simulations into Medical School Curriculum. Concurrent Session presented the annual Association for Educational Communication and Technology conference, Indianapolis, IN. Nov. 4-6.

Hirumi, A., Kleinsmith, A., Johnsen, K., Kubovec, S., Eakins, M., Bogert, K., Rivera-Gutierrez, D., Reyes, R. J., Lok, B., \& Cendan, J. C. (2016a). Advancing virtual patient simulations through design research and InterPLAY: Part I - design and development. Educational Technology, Research \& Development, 64(4), 763-785.
Hirumi, A., Johnson, T., Reyes, R., Johnson, K., Rivera -Gutierrez, D., Kleinsmith, A., Kubovec, S., Eakins, M., Bogert, K., Lok, B., \& Cendan, J. (2016b). Advancing virtual patient simulations through design research and InterPLA Y : Part II testing and integration. Educational Technology, Research \& Development, doi:10.1007/s11423-016 -9461-6.

Issenberg, S. B., McGaghie, W. C., Petrusa, E., Gordon, D. L., \& Scalese, R. J. (2005). Features and uses of high-fidelity medical simulations that lead to effective learning: a BEME systematic review. Medical Teacher, 27(1), 10-28.

Johnson, T.R., Lyons, R., Kopper, R., Johnsen, K. J., Lok, B. C., \& Cendan, J. C. (2014). Virtual patient simulations and optimal social learning context: a replication of an aptitude-treatment interaction effect. Medical Teacher, 36(6), 486-494.

Johnson, T.R., Lyons, R., Chuah, J. H., Kopper, R., Lok, B. C., Cendan, J.C. (2013). Optimal learning in a virtual patient simulation of cranial nerve palsies: The interaction between social learning context and student aptitude. Medical Teacher, 35(1), 899-907.

Kleinsmith, A. D., Rivera-Gutierrez, D., Finney, G., Cendan, J. \& Lok, B. (2015). Understanding empathy training with virtual patients. Computers in Human Behavior, 52, 151-158.

Kolb, D. A. (1984). Experiential learning: Experience as the source of learning and development. Upper Saddle River, NJ: Erlbaum.

Kolb. D. A. \& Fry, R. (1975) Toward an applied theory of experiential learning. In C. Cooper (ed.) Theories of Group Process, London: John Wiley.

LaBar, K. S., \& Cabeza, R. (2006). Cognitive neuroscience of emotional memory. Nature Reviews Neuroscience, 7(1), 54-64.

Li, W., Jiang, Z., Liu, Y., Wu, Q., Zhou, Z., Jorgensen, N., \& Li, C. (2014). Positive and negative emotions modulate attention allocation in color-flanker task processing: Evidence from event related potentials. Motivation and Emotion, 38(3), 451-461.

Lindsey, L., \& Berger, N. (2009). Experiential approach to instruction. In C. Reigeluth and A. CarrChellman (Eds.). Instructional-Design Theories and Models: Vol. 3. Building a Common Knowledge Based (pp. 117-142), New York, NY: Routledge.

Lyons, R., Johnson, T. R., Khalil, M. K., \& Cendan, J. C. (2014). The impact of social context on learning and cognitive demands for interactive virtual human simulations. PeerJ, 2.

Madan, C. R., \& Singhal, A. (2014). Improving the TAMI for use with athletes. Journal of Sports Sciences, 32(14), 1351-1356. 
McGaghie, W. C., Issenberg, S. B., Cohen, M. E. R., Barsuk, J. H., \& Wayne, D. B. (2011). Does simulation-based medical education with deliberate practice yield better results than traditional clinical education? A meta-analytic comparative review of the evidence. Academic medicine: journal of the Association of American Medical Colleges, 86(6), 706.

McKenney, S. E. \& Reeves, T. (2012). Conducting Educational Design Research: What, Why and How. London: Taylor \& Francis Ltd.

Mezirow, J. (1990). Fostering critical reflection in adulthood: A guide to transformative and emancipatory learning. San Francisco. CA: Jossey-Bass.

Moore, F., \& Chalk, C. (2009). The essential neurologic examination: What should medical students be taught? Neurology, 72(23), 2020-2023.

Nieh, E. H., Kim, S., Namburi, P., \& Tye, K. M. (2013). Review: Optogenetic dissection of neural circuits underlying emotional valence and motivated behaviors. Brain Research, 1511, 73-92.

Quinn, C. (2009). Computer-based simulations: Principles of engagement. In M. Silberman (Ed). The Handbook of Experiential Learning (p. 138-171). San Francisco, CA: Pfeiffer.

Reigeluth, C. M., \& Schwartz, E. (1989). An instructional theory for the design of computer-based simulations. Journal of Computer-Based Instruction, 16(1), 1-10.

Reyes, R. \& Hirumi, A. (2016). Analyzing the pedagogical foundations of virtual patient simulations: $A$ review of literature. Poster presented at the annual graduate research forum at the University of Central Florida, Orlando, FL. April 5.

Reyes, R. J., \& Hirumi, A. (2015). Stimulating the imagination to accelerate learning and performance. Roundtable discussion at the annual Association for Educational Communication and Technology conference, Indianapolis, IN. Nov. 4-6.

Rivera-Gutierrez, D., Kleinsmith, A., Johnson, T., Lyons, R., Cendan, J., \& Lok, B. (2014). Towards a Reflective Practicum of Embodied Conversational Agent Experiences. 2014 IEEE 14Th International Conference on Advanced Learning Technologies, 694. doi:10.1109/ICALT.2014.20.

Salas, E., \& Gregory, M.E. (2011). Simulation-based training: Beyond the bells and whistles! CyberTherapy Magazine, 4, 18-19.

Salem-Schatz, S., Ordin, D., \& Mittman, B. (2010). Guide to the After Action Review (Version 1.1). Using Evaluation to Improve Our Work: A Resource Guide. Retrieved 03/23/2015 http:// www.queri.research.va.gov/ciprs/ after_action review.pdf.
Shank, R. C., Berman, T. R., \& Macpherson, K. A. (1992). Learning by doing. In C. M. Reigeluth (Ed). Instructional Design Theories and Models: A New Paradigm of Instructional Theory (pp. 161179). Hillsdale, N.J.: Lawrence Erlbaum Associates.

Stapleton, C., \& Hirumi, A. (2014). Designing InterPLAY learning landscapes to evoke emotions, spark the imagination, and promote creative problem solving. In A. Hirumi (Ed.), Grounded Designs for Online and Hybrid Learning: Practical Guidelines for Educators and Instructional Designers (pp. 159-190). Eugene, WA: International Society for Technology in Education.

Stapleton, C., \& Hirumi, A. (2011). Interplay instructional strategy: Learning by engaging interactive entertainment conventions. In M. Shaughnessy \& S. Fulgham (Eds). Pedagogical Models: The Discipline of Online Teachings (pp. 183-211). Hauppauge, NY: Nova Science Publishers, Inc.

Schon, F., Hart, P., \& Fernandez, C. (2002). Is clinical neurology really so difficult? Journal of Neurology, Neurosurgery \& Psychiatry, 557.

Tia, B., Mourey, F., Ballay, Y., Sirandré, C., Pozzo, T., \& Paizis, C. (2010). Improvement of motor performance by observational training in elderly people. Neuroscience Letters, 480(2), 138-142. 
66 WWW.JAID.PUB - October 2017 • ISSN: 2160-5289 